\title{
APORTACIONES DOCUMENTALES SOBRE EL ESCULTOR PEDRO ROLDÁN
}

\section{DOCUMENTARY CONTRIBUTIONS ON THE SCULPTOR PEDRO ROLDÁN}

\author{
JosÉ LuIs ROMERo TORRES \\ Consejería de Cultura y Patrimonio Histórico, Juan de Andalucía. España \\ ORCID: 0000-0002-4199-3606 \\ joseluisromerotorres@gmail.com
}

\begin{abstract}
El escultor Pedro Roldán nació en Sevilla en 1624, pero se ha investigado poco sobre su extensa familia de Antequera. En esa ciudad nacieron otros hermanos mayores que el artista y uno menor que se desconocían hasta ahora. Con esta documentación se afianza la hipótesis de que la infancia y los inicios de su formación artística transcurrieron en Antequera. En este artículo se aportan nuevos documentos sobre sus abuelos, padres, hermanos, tíos, sobrinos y primos de Antequera y Archidona; y se aclaran algunas homonimias. También se da a conocer nueva información familiar sobre el escultor Julián Roldán Guerrero, quien aprendió y trabajó con Pedro Roldán. Entre esos documentos: el matrimonio de los padres, su nacimiento en Archidona en 1637, el de sus hermanos y la muerte de su padre.

Palabras clave: escultura barroca; Pedro Roldán; Antequera; Julián Roldán; Archidona.
\end{abstract}

The sculptor Pedro Roldán was born in Seville in 1624, but little research has been done on his extended family from Antequera. In that city were born other brothers older than the artist and a younger one who were unknown until now. This documentation reinforces the hypothesis that childhood and the beginnings of his artistic training took place in Antequera. In this article new documents are provided about his grandparents, parents, brothers, uncles, nephews and cousins of Antequera and Archidona; and some homonymies are clarified. New family information about the sculptor Julián Roldán Guerrero, who learned and worked with Pedro Roldán, is also released. Among those documents: the marriage of the parents, his birth in Archidona in 1637, that of his brothers and the death of his father.

Keyword: Baroque sculpture; Pedro Roldán; Antequera; Julián Roldán; Archidona. 
La vida del escultor sevillano Pedro Roldán el Viejo está estrechamente relacionada con la ciudad de Antequera, en la que nacieron o vivieron otros artistas que se establecieron definitivamente en Sevilla y mantuvieron amistad entre ellos $^{1}$, como el arquitecto y ensamblador Bernardo Simón de Pineda ${ }^{2}$, el platero José Portillo ${ }^{3}$ y el arquitecto Leonardo de Figueroa ${ }^{4}$. Otro artista cuya familia residió muchos años en esa localidad y también terminó por afincarse en la ciudad hispalense fue el escultor José Montes de Oca ${ }^{5}$.

Palomino y Ceán Bermúdez informaron que Pedro Roldán era sevillano ${ }^{6}$, pero en 1928 el profesor Antonio Gallego y Burín publicó la noticia de que había nacido en Antequera y que recibió su aprendizaje en Granada en el taller de Alonso de Mena y Escalante, según se desprendía de su expediente matrimonial ${ }^{7}$. Años después, Heliodoro Sancho Corbacho publicó en 1950 un amplio expediente de la familia Roldán, localizado en el archivo de protocolos notariales de Sevilla, en el que se incluían partidas sacramentales desde el siglo XVI procedentes de parroquias de Antequera, Archidona y Sevilla, y entre ellas el bautismo de Pedro Roldán celebrado el 14 de enero de 1624 en la iglesia del Sagrario de Sevilla. Con ese expediente aclaraba la naturaleza del artista y la vinculación antequerana de sus antepasados ${ }^{8}$, pero generaba una pequeña confusión con la lectura del lugar de donde procedía el artista: Gallego Burín (1925) leyó Antequera, el archivero arzobispal que transcribió el documento para Sancho Corbacho (1950) entendió Orce y la historiadora Salazar Bermúdez (1955) volvió a leer el documento y confirmó que el texto decía Antequera ${ }^{9}$. No obstante, algunas reseñas biográficas del escultor siguen repitiendo la errónea referencia a Orce.

A la luz de la información, Sancho Corbacho expuso las conclusiones de su investigación en el apartado titulado "La verdadera patria de Pedro Roldán", desglosándolas en seis puntos, en algunos planteaba dudas que se aclaran en este artículo:

${ }^{1}$ Romero Torres, $2020 b$.

2 Romero Benítez, 1989: 147-168. Romero Torres, 2004:170-171.

3 Santos Márquez, 2009: 431-440.

${ }^{4}$ Higuera Meléndez, 2012-2013: 9-44; 2013: 261-288.

${ }^{5}$ Romero Torres, 2020a.

${ }^{6}$ Palomino, 1724. Ceán Bermúdez, 1800: IV, 240.

7 Gallego, 1925: 330-331. El expediente matrimonial dice: "que se llama Pedro Roldán, que es de edad de diez y ocho años, poco más o menos, hijo de Marcos Roldán, carpintero, difunto y de Ysabel de Nieves, que es natural de la ciudad de Antequera y que había cuatro años que se vino a esta ciudad a casa de Alonso de Mena". La abreviatura de Antequera es la que fue leía incorrectamente por Orce.

${ }^{8}$ Sancho Corbacho, 1950: 13, 83.

9 Salazar Bermúdez, 1955: 13, 15, 63-66; 1949: 317-340. 
- “a) Marcos Roldán e Isabel de Nieva, naturales y vecinos de Antequera, casaron en esta ciudad el 22 de febrero de 1609. Desconocemos si tuvieron en ella a su hijo Marcos; pero lo indudable es que algún tiempo después de su matrimonio, en fecha y por causas desconocidas, se trasladaron a Sevilla”. Después de las nupcias, Marcos e Isabel permanecieron en Antequera once años en donde nacieron siete hijos, entre ellos el primogénito llamado Marcos, y entre 1620 y 1623 se trasladaron a Sevilla, donde nació Pedro Roldán.

- “c) Por causas asimismo desconocidas y desconociendo también la fecha, se ausentaron de Sevilla los padres de Pedro Roldán, quienes, en unión de su hijo que debía constar muy poca edad, se trasladaron, al parecer, a Orce donde se establecieron". Después del nacimiento de Pedro Roldán, el matrimonio y sus hijos volvieron a Antequera, en donde nació el noveno vástago de los Roldán-Nieva.

- “d) En la ciudad de Orce murió Marcos Roldán, y su hijo Pedro, contando 14 años de edad, salió el año 1638 con dirección a Granada, a aprender el arte de la escultura en el taller de Alonso de Mena".

- "e) No extraña que declarara en el expediente matrimonial que era natural de la ciudad de Orce, si se tiene en cuenta que había vivido casi todo el tiempo en aquella ciudad". La lectura de Orce fue errónea, porque la abreviatura era Antequera.

\section{CONFUSIONES SOBRE LA FAMILIA DE PEDRO ROLDÁN}

Desde 1950 no ha habido nuevos documentos sobre los antecedentes familiares y la infancia de Pedro Roldán. La última monografía de Pedro Roldán, escrita magistralmente por el profesor José Roda ${ }^{10}$, recoge los datos antequeranos aportados por Sancho Corbacho: el casamiento de Juan Roldán Conejo y María Alonso Sánchez -abuelos del escultor- en $1573^{11}$; el nacimiento de tres hijos, Juan, María y Marcos; los casamientos de los varones, el primogénito con Inés de Estudillo en 1597 y Marcos Roldán Alonso con Isabel de Nieva en 1609, padres del escultor; así como la existencia de dos hijos de este último matrimonio, Marcos y Pedro -el escultor-. No obstante, Sancho Corbacho cometió dos equivocaciones: una, confundir Isabel de Nieva o Neva con su nuera Isabel Fresneda Gavilán y, otra, el parentesco entre el matrimonio Marcos Roldán e Inés de la Hixa y el escultor, pues ese Marcos no era su tío, sino su sobrino, por lo que el escultor Julián Roldán Guerrero era sobrino nieto. La confusión se produjo porque desconoció que hubo tres Marcos Roldán -padre, hijo y nieto- que los hemos identificado con la numeración romana en el cuadro genealógico que presentamos. Entre los dos Marcos que menciona Sancho Corbacho existió otro homónimo que no apreció. Por lo tanto,

\footnotetext{
${ }^{10}$ Roda Peña, 2012: 73-74.

${ }^{11}$ Sancho Corbacho, 1950: 73.
} 
la descendencia por primogenitura fue: Marcos Roldán I e Isabel de Nieva, padres de 9 hijos, entre ellos el escultor; Marcos Roldán II, hijo del anterior Marcos, hermano del escultor y marido de Isabel Fresneda Gavilán; y Marcos Roldán III, nieto del primero, sobrino del escultor, marido de Inés de la Hixa y padre del escultor Julián Roldán Guerrero y de dos hijos más llamados Pedro y Manuel.

\section{ANTECESORES ANTEQUERANOS}

En la historia familiar de Pedro Roldán existe una amplia homonimia que ha generado confusión en la identificación de algunos de sus miembros, como ha señalado el profesor Manuel García Luque en su artículo sobre Pedro Roldán, el $\mathrm{mozo}^{12}$. Esa repetición de nombres en varias generaciones también sucede con sus antepasados, principalmente con los nombres de Juan, Marcos y Pedro, como se analiza en este artículo, por lo que los hemos diferenciado con la numeración romana.

El primer nivel o generación del contexto familiar que nos interesa lo iniciamos con la boda de sus abuelos, Juan Roldán I y María Alonso Sánchez, el 16 de agosto de 1573 en la parroquia de Santa María de Antequera, que dio a conocer Sancho Corbacho ${ }^{13}$. Ella era hija de Juan Alonso y los padrinos fueron Pedro Verdugo y Juana Muñoz.

La segunda generación, la de Roldán-Alonso, son los hijos de ese matrimonio, que no fueron tres como se ha escrito ${ }^{14}$, sino seis ${ }^{15}$ : Juan II (1574), Alonso (1581), Ana (1585), Marcos I (1589), Francisco (1592) y Pedro I (1596). Marcos, que será el padre del escultor sevillano, fue bautizado el 1 de mayo en la parroquia de Santa María y sus padrinos fueron Martín Jiménez y su mujer Ana Gonzále $z^{16}$. Los nacimientos se distanciaron tanto que un año después del último hijo se casó el primogénito, Juan Roldán II, quien inició una rama familiar a partir de su boda el 7 de diciembre de 1597 con Inés de Estudillo en la parroquia de

12 García Luque, 2016: 191-218.

13 Sancho Corbacho, 1950: 13, 73, apéndice III, doc. 2 y 3. AHMAnt (Archivo Histórico Municipal de Antequera), Sección Parroquias, L. 48, Parroquia de Santa María, Matrimonios, libro 1, 1569-1594, f. 21.

${ }^{14}$ Sancho Corbacho, 1950: 90-91.

15 AHMAnt, Sección Parroquias, L. 20, Parroquia de Santa María, Bautismos, libro 1, 1564-1579, f. 183 (Juan, 18 de julio, padrinos Hernán Martín y su mujer María Sánchez); Ibidem, L. 21, Parroquia de Santa María, Bautismos, libro 3, 1580-1601, f. 30v (Alonso, 21 de septiembre, padrinos Antón Sánchez Cantós [sic] y Juana Martín, su mujer); f. 87v (Ana, 14 de julio, padrinos Alonso Ximénez y María Carrizo, su mujer); f. 122 (Marcos, 1 de mayo, padrinos Martín Ximénez y Ana González, su mujer); f. 160 (Francisco, 2 de febrero, padrinos Martín Ximénez y Ana González, su mujer); f. 221 (Pedro, 19 de noviembre, padrinos Antón de Carlos [sic] y María de Espinosa, su mujer).

${ }^{16}$ Sancho Corbacho, 1950: 90-91. 
Santa María de Antequera. Ella era viuda e hija de Francisco Moreno y Juana Rodríguez, fueron testigos Bartolomé de Medina y Juan de Bobadilla ${ }^{17}$. Y al mes siguiente, 18 de enero de 1598, recibieron las velaciones nupciales en la misma iglesia, siendo sus padrinos Bartolomé de Molina y su mujer Catalina Martín. Años más tarde, el 23 de abril de 1602, ella enfermó y decidió redactar testamento, por el que sabemos que su marido, Juan Roldán II, era de profesión calderero, a quien nombró albacea junto a Bartolomé de Molina ${ }^{18}$. Ella no murió en esa ocasión. Este Bartolomé de Molina estuvo muy vinculado a la familia, como veremos en este artículo, y tenía el mismo oficio que Juan Roldán II. El matrimonio tuvo un hijo al que llamaron Juan, homónimo a su padre y el tercero de ellos.

El 1 de mayo de 1627, Juan Roldán II -hijo de Juan Roldán I y María Alonso, esposo de Inés de Estudillo y tío del escultor Pedro Roldán- fue enterrado en la parroquia de Santa María ${ }^{19}$. En el documento parroquial no se especifica de quién es marido, pero en el testamento declaró que su mujer era Inés de Estudillo, a quien nombró albacea junto a su hermano Francisco Roldán, vecinos de Antequera, y que su heredero era su hijo Juan Roldán, el tercero del árbol genealógico ${ }^{20}$. En su testamento destacamos que tenía a su cargo la renta del almojarifazgo de esa ciudad; que Bartolomé Salas le debía ciertas cantidades; y que a su esclavo lo pusieran a aprender un oficio para que pudiera ser libre. Asimismo, declaró que había recibido dote y que estuvo encargado de la tutoría de los hijos menores de su hermano Alonso. Su mujer se encargó de las gestiones post mortem: hizo escritura notarial con el zapatero Bartolomé de Salas ${ }^{21}$ y junto a su hijo Juan Roldán, cerrajero, otorgó poder al procurador Alonso de Cavallta [sic]. Ella murió el 11 de enero de 1635 y fue enterrada en la parroquia de Santa María ${ }^{22}$. Hizo testamento el día 9 ante el escribano Bartolomé Jiménez del Águila ${ }^{23}$. Además de las misas y mandas habituales, declaró que no debía nada e hizo relación de las personas que le debían. También mencionó los datos de su matrimonio y nombró heredero a su único hijo, a quien también nombra albacea junto a "Ana María de Estudillo, su mujer y mi nuera". Sancho

17 Ibidem, p. 74. AHMAnt, Sección Parroquias, L.49, Parroquia de Santa María, Matrimonios, libro 2, 1594-1612, f.35 (matrimonio y velaciones nupciales).

${ }_{18}$ AHMAnt, Sección de Protocolos Notariales de Antequera, sign. C. 1880, f. 550-552.

19 AHMAnt, Sección Parroquias, L. 82, Parroquia de Santa María, Testamentos (Entierros), libro 1, 1607-1697, f. 9.

20 AHMAnt, Sección Protocolos Notariales de Antequera, sign. C. 2105, ff. 249v-252, 5 de mayo de 1627, escribano Gonzalo Fernández Alba.

${ }^{21}$ Ibidem, ff. $256257 \mathrm{v}, 7$ de mayo; f. 369 r y v.

${ }^{22}$ AHMAnt, Sección Parroquias, L. 82, Parroquia de Santa María, Testamentos (Entierros), libro 1, 1607-1697, f. 14v.

${ }^{23}$ AHMAnt, Sección Protocolos Notariales de Antequera, Sign. C. 861, ff. 21-22v, 9 de enero de 1635, escribano Bartolomé Jiménez del Águila. 
Corbacho creyó que esta Inés y su nuera Ana María eran la misma persona, porque las dos llevaron el apellido Estudillo.

Marcos Roldán I e Isabel de $\mathrm{Nieva}^{24}$, padres del escultor, contrajeron matrimonio y recibieron las velaciones el 22 de febrero de 1609 en la parroquia de San Sebastián de Antequera, como publicó Sancho Corbacho ${ }^{25}$. Ella era hija de Alonso Gómez y de Isabel de Nieva, y sus padrinos fueron Manuel Gómez y Quiteria González. Este contexto familiar antequerano del escultor Pedro Roldán se completa con sus ocho hermanos nacidos en esa ciudad malagueña, de los que sólo se conocía la existencia de uno.

En la tercera generación destacamos dos ramas: Roldán-Estudillo y RoldánNieva. Como acabamos de documentar, el matrimonio Juan Roldán II e Inés de Estudillo tuvieron un hijo, homónimo a su padre, que nació en 1603 en Antequera $^{26}$. Juan Roldán III entroncó en 1624 con una familia de la localidad cercana de Archidona mediante su casamiento con Ana María del Espíritu Santo que también era Estudillo de segundo o tercero apellido, donde se afincarán varias generaciones de esta rama ${ }^{27}$.

La rama Roldán-Nieva es la que más nos interesa. Al final del año de la boda de los padres del escultor Pedro Roldán el Viejo en 1609, nació el primogénito Roldán-Nieva que el 6 de diciembre fue bautizado con el nombre de Marcos, el segundo de esta familia, en la parroquia de Santa María de Antequera, siendo sus padrinos Bartolomé de Molina y Catalina Martín, su mujer ${ }^{28}$. El documento informa que Alonso de Luque, beneficiado de San Isidro, "echó de agua en su casa por necesidad que tuvo". Cada dos años siguió naciendo un hijo o hija y, casi todos, fueron bautizados en la misma parroquia antequerana de Santa María. En 1611 fue María $^{29}$ y dos años después nació Isabel ${ }^{30}$, cuyos padrinos fueron los

${ }^{24}$ Desde que Gallego Burín publicó la noticia del expediente matrimonial del escultor Pedro Roldán se viene dudando del apellido correcto de la madre. En ese artículo se decía Onieva. Cuando Sancho Corbacho publicó la partida de bautismo del escultor y la llamó Nieva, la que creemos correcta. A pesar de que, en el registro matrimonial de Marcos e Isabel -los padres del escultor-, ella está escrita como Neva y en los bautismos de sus hijos hay variedad de opciones: Nieves, Onieva, Nieba, Nieva y Niebla. En otros documentos se escribe Donieva.

${ }^{25}$ Sancho Corbacho, 1950: 91-92. AHMAnt, Sección Parroquias, L. 504, Parroquia de San Sebastián, Matrimonios, libro 3, 1606-1624, f. 58.

${ }^{26}$ Ibidem, L. 22, Parroquia de Santa María, Bautismos, libro 4, 1601-1623, f. 29.

27 AHDMal (Archivo Histórico Diocesano de Málaga), Sección Archidona, Matrimonios, libro 4, 1621-1635, f. 80. Agradezco a Gonzalo Otalecu y a Alberto Castro Tirado la localización de todos datos sacramentales procedentes de este archivo.

28 AHMAnt, Sección Parroquias, L. 22, Parroquia de Santa María, Bautismos, libro 4, 1601-1623, f. 111v. La madre con el apellido Nieves.

${ }^{29}$ Ibidem, f. 131, María, 22 de julio, la madre con el apellido Onieva.

${ }^{30} \mathrm{Ibid}, \mathrm{f}$. 153v, Isabel, 27 de enero, la madre con el apellido Onieva. 
mismos de su hermano mayor, y en 1614 lo nació el segundo varón llamado Damián, cuyos padrinos fueron Juan de Padilla Carrasco y Luisa Díaz ${ }^{31}$.

En esos años existen dos arrendamientos de casas realizados por un Marcos Roldán que era de oficio de calderero, que dudamos fuera el padre del escultor sevillano, pues, según el expediente matrimonial del escultor, era carpintero ${ }^{32}$. No obstante, nos parece de interés. El 11 de abril de 1611, Marcos Roldán, calderero, recibió en arrendamiento unas casas de Pedro Gómez Gavilán en la calle Caldereros de Antequera que lindaban con casas del propietario por dos años ${ }^{33}$. Nuevamente, el 23 de enero de 1616, esta misma persona se obligó a pagar 7 ducados y medio al barbero Francisco Rodríguez Santos por el arrendamiento de otra casa en la misma calle. Entre los testigos, figuran el calderero Bartolomé de Molina y el hijo de este y homónimo ${ }^{34}$. Curiosamente ese Bartolomé es el padrino de algunos hermanos del escultor Pedro Roldán. En 1617, Marcos Roldán, calderero, se querelló contra Juan Rodríguez Morente y su hijo Andrés porque habían matado a su hijo Damián al volcarse un carro, y el 16 de septiembre de ese año el querellante formalizó un documento notarial en el que perdona a la familia de Juan Rodríguez ${ }^{35}$. Como se aprecia este Marcos Roldán tuvo un hijo Damián, como el primogénito de la rama Roldán-Nieva, pero este no puede ser el mismo porque nació en 1609. Futuras investigaciones conseguirán aclarar la duda profesional de Marcos Roldán I y la relación familiar con el que protagoniza los citados documentos.

El matrimonio Roldán-Nieva siguió teniendo hijos cada dos años: en 1616 fue bautizada Lucía en la parroquia de Santa María ${ }^{36}$, siendo sus padrinos los mismos de su hermano mayor, Bartolomé de Molina y Catalina Martín. La familia debió de trasladar la vivienda a la parroquia de San Juan Bautista, pues en esa iglesia fue bautizada Catalina el 2 de diciembre de 1618 y sus padrinos fueron nuevamente los de sus hermanos Marcos, María, Isabel y Lucía ${ }^{37}$. La estancia en aquel barrio fue breve, pues los Roldán-Nieva volvieron a la feligresía de Santa María donde nació el séptimo hijo, quien el 11 de octubre de 1620 recibió

${ }^{31}$ Ibid, f. 181, 23 de noviembre, la madre con el apellido Nieba.

${ }^{32}$ Sancho Corbacho, 1950: 15, 49.

33 AHMAnt, Protocolos Notariales de Antequera, Legajo 1677, ff. 183 r y v.

${ }^{34}$ Ibidem, sign. C. 1115 , ff. $176 \mathrm{r}$ y v.

${ }^{35}$ Ibid, sign. C. 1239, ff. 470, r y v, escribano Juan de Palacios Vallejo.

${ }^{36}$ AHMAnt, Parroquias, L. 22, Parroquia de Santa María, Bautismos, libro 4 (16011623), f. 219, 17 de diciembre, la madre con el apellido Nieba.

37 Ibidem, L. 128, Parroquia de San Juan Bautista, Bautismos, libro 3 (1617-1638), f. $20 \mathrm{v}$, la madre con el apellido Nieva. 
el nombre de Francisco en esa parroquia, y los padrinos fueron Martín Vázquez y Lucía Martín ${ }^{38}$.

A partir de esa fecha se pierde temporalmente la pista de esta familia RoldánNieva en Antequera, apareciendo en Sevilla en 1624, cuando el 14 de enero fue bautizado el escultor Pedro Roldán en la parroquia del Sagrario ${ }^{39}$. En ese mismo año, su primo Juan Roldán Estudillo, el tercer Juan Roldán, contrajo matrimonio en Archidona.

Ahora conocemos que la familia Roldán-Nieva volvió a Antequera y nuevamente residió en el barrio de San Juan Bautista en cuya parroquia fue bautizada su hija Antonia en 1626, y su padrino fue Francisco Roldán ${ }^{40}$, que identificamos con su tío. Existe un vacío documental en los libros de entierros de esta parroquia en esas décadas, lo que impide conocer si el padre del escultor murió en Antequera, pues en el expediente matrimonial de Pedro Roldán en 1642 se especifica que era difunto.

En la cuarta generación destacamos tres ramas: Roldán-Estudillo, RoldánFresneda y Roldán-Villavicencio/Ortega/Mena. En la primera rama destacan los hijos Francisco y Juan, sobrinos del escultor Pedro Roldán el Viejo. Al primero, lo identificamos con el fiador del escultor Pedro Roldán el Mozo en el contrato del retablo que hizo en 1697 para la hermandad de Jesús Nazareno de Archidona; quien firmó "Francisco Roldán y Estudillo Conejo" ${ }^{41}$, por lo que eran primos segundos. La rama Roldán-Fresneda se desarrolla en el apartado que hemos titulado "El escultor archidonés Julián Roldán Guerrero". Y la tercera rama es la de Roldán-Ortega/Villavicencio/Mena, que corresponde a los hijos del matrimonio del escultor Pedro Roldán el Viejo con Teresa de Jesús Ortega, quien también usó los apellidos de Villavicencio y Mena: María (1644), Teodora Manuela (1646), Pedro Mauricio (1647), Francisca Antonia (1650), Luisa (1652), María Josefa (1654), Manuel Fulgencio (1657), Isabel (1658), Teresa Josefa (1660), los gemelos Ana Manuela y Marcelino José (1662) y Pedro de Santa María, más conocido como Pedro Roldán el Mozo (1665). La primera nació en Granada y los demás hijos e hijas en Sevilla. De las 8 hembras y 4 varones, sólo vivían 6 hijas y dos hijos cuando el escultor Pedro Roldán el Viejo murió en 1699. De ellos, cinco desarrollaron la actividad artística: Francisca era policromadora; y Luisa, María, Marcelino y Pedro el Mozo siguieron el oficio de su padre.

${ }^{38}$ Ibidem, L. 22, Parroquia de Santa María, Bautismos, libro 4 (1601-1623), f. 284v, la madre con el apellido Nieva.

${ }^{39}$ Sancho Corbacho, 1950: 83.

40 AHMAnt, Parroquias, L. 128, Parroquia de San Juan Bautista, Bautismos, libro 3, 1617-1638, f. 149. Apellido Niebla.

${ }^{41}$ Garrido Pérez, 2010: 321-332. Posteriormente, se ha aclarado que este escultor era el hijo del maestro Pedro Roldán el Viejo. García Luque, 2016: 203-204. 


\section{INFANCIA Y JUVENTUD DEL ESCULTOR PEDRO ROLDÁN EL VIEJO}

Existe un vacío documental en los libros de entierros de la parroquia de San Juan Bautista de Antequera en las décadas de 1620 y 1630, por lo que desconocemos si Marcos Roldán I murió en esa ciudad, pues en el expediente matrimonial de Pedro Roldán el Viejo se especifica que era difunto en 1642. Y si en ese documento se acepta una lectura incorrecta de la abreviatura Antequera por Orce, podemos considerar que la familia continuó durante años en esa ciudad malagueña, entre el bautismo de Antonia Roldán Nieva, hermana pequeña del escultor Pedro Roldán el Viejo, y el año 1638, cuando este ingresó en el taller granadino.

Si Marcos Roldán I era carpintero, como se declara en el expediente matrimonial de Pedro Roldán, este se inició, sin duda, en el manejo de las herramientas de la talla de la madera en el taller paterno. Y, en el supuesto de que la familia permaneció en Antequera, el joven Pedro pudo haber iniciado su aprendizaje hacia 1635 en el arte de la escultura junto al maestro Juan Bautista del Castillo. Él tendría once o doce años, la edad prevista en las ordenanzas gremiales, pues hasta los 14 años no ingresó en el taller de Alonso de Mena y Escalante en Granada. Dejamos planteado esta hipótesis para futuras investigaciones.

En Antequera estaba activo el escultor Juan Bautista del Castillo (15811657), hermano mayor de Pedro Sánchez que entró en 1605 en el taller de Martínez Montañés con la edad de 12 años $^{42}$. Los dos eran hijos del alarife Francisco Sánchez del Castillo. Juan Bautista es autor de esculturas de gran expresividad con anatomía de musculatura pronunciada, como el denominado "Ecce Homo" de la iglesia de Nuestra Señora del Carmen y el Crucificado expirante, hacia 1652, de la iglesia de San Pedro, ambas con la advocación de las Penas. La mencionada imagen del Carmen está concebida de rodillas con las manos juntas delante del pecho y con la mirada implorante hacia arriba, una composición que también fue representada por los hermanos García, artistas granadinos coetáneos a Castillo. Pedro Roldán pudo aprender esta iconografía en Antequera o Granada, pues el artista sevillano hizo una interpretación con un sentido barroco más profundo en 1674 en el Cristo de la Caridad del altar lateral de esa advocación del Hospital de la Santa Caridad de Sevilla. En 1618, Castillo también realizó el San Juan Bautista del altar mayor de la parroquia antequerana, en cuyo barrio vivió temporalmente la familia Roldán-Nieva. También se le atribuyen dos esculturas de Crucificado expirante (Museo Conventual de las Descalzas y Convento de Carmelitas Descalzas). Este escultor tuvo dos hijos artistas: Francisco fue pintor y Antonio siguió el oficio de su padre. El estilo artístico de este último refleja la influencia granadina del arte de Pedro de Mena y de José de Mora ${ }^{43}$.

\footnotetext{
${ }^{42}$ Romero Torres, 2011: 65-67.

${ }^{43}$ Romero Benítez, 2013: 43-47. Escalante Jiménez, 2019: 116-121. Sánchez López, 2015: 86-87.
} 


\section{EL ESCULTOR ARCHIDONÉS JULIÁN ROLDÁN GUERRERO}

La rama Roldán-Fresneda (cuarta generación) surge del matrimonio de Marcos Roldán II, hermano mayor del escultor sevillano, con Isabel Fresneda Gavilán. Entre los dos hermanos hubo una diferencia de 15 años y los dos primeros nietos de Marcos nacieron antes de la boda de Pedro Roldán y Teresa Ortega Villavicencio. Marcos e Isabel tuvieron un solo hijo que fue Marcos Roldán III, quien contrajo nupcias el 22 de octubre de 1634 en la parroquia de Santa Ana de Archidona con Inés de la Hija Guerrero, hija de Alonso García Guerrero y Ana María de Padilla ${ }^{44}$. Padre e hijo fueron de oficio calderero. Celebró la ceremonia el licenciado Pedro de Albuquerque, comisario del Santo Oficio de la Inquisición, vicario y cura de la parroquia de Santa Ana sin haber procedido las tres amonestaciones por mandamiento del provisor de Málaga que los dispensó. Los testigos fueron el licenciado y presbítero Pedro de Estudillo, Francisco Ximénez de Estudillo y Francisco del Moral. Los Estudillos estaban emparentados con otra rama de la familia Roldán. La pareja Marcos e Inés generó la rama Roldán Guerrero y tuvieron tres hijos: Julián (1637), Pedro (1638) y Manuel (1640).

El primero de los tres hijos fue el escultor Julián Roldán Guerrero que ha tenido poca fortuna artística. Ceán Bermúdez confundió a los escultores Julián Roldán Guerrero y Marcelino Roldán Serrallonga en la breve biografía del segundo ${ }^{45}$. También ha generado confusión la información extraída del expediente matrimonial de Marcelino Roldán, del que se ha deducido que Julián, quien declaró de testigo del contrayente, nació hacia 1650. Por otra parte, la historiografía sevillana lo ha considerado sobrino de Pedro Roldán, pero, en realidad, fue sobrino nieto ${ }^{46}$.

Julián Roldán Guerrero era hijo de Marcos Roldán III y de Inés de la Hija Guerrero, y nieto de Marcos Roldán II e Isabel Fresneda Gavilán, según la declaración que hizo su abuelo materno Alonso García Guerrero - padre de la referida Inés- con fecha de 21 de marzo de 1652 en Archidona $^{47}$, datos confirmados con los documentos que exponemos.

El 11 de enero de 1637, Juan Crespo de Cabrera, cura de la parroquia de Santa Ana de Archidona y numerario del Santo Oficio de la Inquisición, bautizó a Julián, hijo de Marcos Roldán III e Inés de la Hija Guerrero, su mujer. Fueron sus padrinos Bartolomé de Casasola y su mujer Mencía de la Hija ${ }^{48}$. Al año siguiente, nació otro hijo del matrimonio al que bautizaron el 16 de agosto de 1638

44 AHDMal, Sección Archidona, Matrimonios, libro 4 (1621-1635), f. 264v, 22 de octubre.

45 Ceán Bermúdez, 1800: IV, 239-240.

46 Torrejón Díaz, 2007: 72.

47 Sancho Corbacho, 1950: 86-89.

48 AHDMal, Sección Archidona, Bautismos, libro 16 (1636-1640), f. 53v. Agradezco la localización de la partida a Gonzalo Otalecu. 
en la misma parroquia con el nombre de Pedro y fueron sus padrinos Pedro y Clara de la Barrera ${ }^{49}$. Y, por último, el 3 de junio de 1640 bautizaron en la misma parroquia al tercer hijo con el nombre de Manuel $^{50}$.

Por ello, se descarta que Julián naciera en 1650, como se ha escrito. Y, además, fue imposible porque su padre estaba muerto en 1641, cuando Inés de la Hija figura como viuda de Marcos Roldán en un documento fechado el 9 de mayo de ese año. Inés de la Hija cedió a su cuñado Francisco Roldán, de oficio calderero, los utensilios de ese oficio que eran de su marido difunto: calderas, candiles, tenazas, cazos, yunques, tijeras, cobre, otros metales, etc. ${ }^{51}$. En ese documento, también se incluye el arrendamiento de unas casas, vivienda y tienda, en la calle Salazar de Archidona por dos años en precio de 30 reales y media anuales, cuyo edificio lindaba con casas de Alonso García Guerrero, padre de Inés. Al mes siguiente, la misma señora y su cuñado volvieron a formalizar otro documento de venta de herramientas del mismo oficio, siendo testigo el padre de ella que firmó: "Alonso Guerrero" 52 .

Por la declaración de Alonso García Guerrero en 1652, como abuelo de Julián, Pedro y Manuel Roldán Guerrero, se sabe que Julián y su hermano Manuel ya vivían en Sevilla en ese año, mientras el otro hermano seguía estando en Archidona $^{53}$. En ese año Julián tenía 15 años, por lo que estaba en plena etapa de aprendizaje. En 1658 y siguientes años Julián vivía en casa de Pedro Roldán como registran los padrones parroquiales de Santa María Magdalena ${ }^{54}$. En 1667 figura como oficial de escultor junto a su tío abuelo y dos más tarde ya era maestro.

El padre del escultor archidonés no era el hermano del escultor Pedro Roldán, sino el sobrino, por lo que Julián Roldán Guerrero era su sobrino nieto. Él trabajó en 1675 y 1676 con su tío abuelo en la Catedral de Jaén ${ }^{55}$. La última fecha conocida es la de 1688 , en la que es clérigo de órdenes menores y estaba preso en la cárcel eclesiástica ${ }^{56}$.

49 Ibidem, f. 138.

${ }^{50}$ Ibid, libro 17 (1640-1645), f. 7.

${ }^{51}$ AHMArch (Archivo de Protocolos Notariales de Archidona), escribano Fernando Gómez de Silbera, 1641, ff. 80-81v. Agradezco a Manuel Garrido Pérez y a Juan José Jiménez Maldonado la documentación procedente de este archivo archidonense, así como la ayuda a la localización de otros documentos notariales de Antequera.

${ }^{52}$ Ibidem, ff. 92-93v, 18 de junio.

${ }^{53}$ Sancho Corbacho, 1950: 86-88.

${ }_{54}^{54}$ Roda Peña, 2012: 177; 2018: 83, 91.

55 Galera Andreu, 1998: 31-40.

56 Salazar Bermúdez, 1949: 332. Roda Peña, 2012: 177. 


\section{CONCLUSIÓN}

El escultor Pedro Roldán, nacido en Sevilla casi por casualidad y perteneciente a una familia antequerana, tuvo ocho hermanos, desconocidos hasta ahora, que nacieron en Antequera, siete de ellos mayores que el escultor y una hermana menor. Pedro Roldán fue el octavo hijo del matrimonio Marcos Roldán e Isabel de Nieva. Después de su nacimiento en Sevilla, la familia volvió a Antequera donde el escultor vivió su infancia y comienzo de su juventud. La formación artística lo desarrolló en Granada en el taller del escultor Alonso de Mena y Escalante, en cuya ciudad contrajo matrimonio y tuvo su primera hija. Después se estableció en Sevilla, en cuya ciudad vivió el resto de su vida. Por la calidad artística de sus obras y por el número de discípulos fue el gran maestro del último tercio del siglo XVII. En su taller familiar trabajaron sus hijos, hijas, yernos y su sobrino Julián Roldán Guerrero.

De los hermanos del escultor que permanecieron en Antequera, algunos se vincularon con familias del pueblo cercano de Archidona, como sucedió con la descendencia de Marcos Roldán, homónimo de su padre y el primogénito de esa generación, de cuya rama desciende el escultor Julián Roldán Guerrero, uno de los discípulos de Pedro Roldán, cuya partida de bautismo en Archidona se aporta en este estudio. La presencia de Julián en el taller de Pedro Roldán confirma que, desde Sevilla, este artista siguió manteniendo vínculos con su familia antequerana.

Fecha de recepción: 30 de octubre de 2020.

Fecha de aceptación: 2 de mayo de 2021.

\section{BIBLIOGRAFÍA}

Ceán Bermúdez, Juan Agustín (1800): Diccionario histórico de los más ilustres profesores de las Bellas Artes en España. Madrid: Real Academia de Bellas Artes de San Fernando.

Escalante Jiménez, José (2019): El círculo artístico antequerano. Siglos XV-XVII. Antequera: ExLibric.

Galera Andreu, Pedro A. (1998): "Pedro Roldán en la Catedral de Jaén. Nuevas precisiones documentales". En: Códice, 14, pp. 31-40.

Gallego Burín, Antonio (1925): "Tres familias de escultores: los Menas, los Moras y los Roldanes". En: Archivo Español de Arte y Arqueología, 3, pp. 330-331.

García Luque, Manuel (2016): "Un problema de homonimia: reconsiderando al escultor Pedro Roldán, el mozo”. En: Laboratorio de Arte, 28, pp. 191-218.

Garrido Pérez, Manuel (2010): "Pedro Roldán en Archidona: documentación sobre un retablo desaparecido". En: Cuadernos de Arte, 41, pp. 321-332.

Higuera Meléndez, José Manuel (2012-2013): "Leonardo de Figueroa. Orígenes, aprendizaje y comienzos del maestro del barroco sevillano". En: Boletín de la Real Academia de Bellas Artes de San Fernando, 114-115, pp. 9-44. 
(2013): "Leonardo de Figueroa. Inicios y actividad pericial. Una obra y un testamento inéditos". En: Anuario de historia de la iglesia andaluza, VI, pp. 261-288.

Palomino de Castro y Velasco, Antonio (1724/1947): El Parnaso español pintoresco laureado. Madrid: Aguilar.

Roda Peña, José (2012): Pedro Roldán, escultor, 1624-1699. Madrid: Arco Libros. (2018): "La escultura sevillana del pleno Barroco y sus protagonistas durante la segunda mitad del siglo XVII". En: Gila Medina, Lazaro/Herrera García, Francisco Javier (coord.): El triunfo del Barroco en la escultura andaluza e hispanoamericana. Granada, pp. 83, 91.

Romero Benítez, Jesús (1989): "Infancia y obras antequeranas del retablista Bernardo Simón de Pineda”. En: Boletín de Arte, 3, pp. 147-168.

(2013): Antonio del Castillo. Escultor antequerano, 1635-1704. Antequera: Chapitel.

Romero Torres, José Luis (2004): "La escultura y el patrimonio artístico de las Colegiatas de Antequera”. En: Romero Benítez, Jesús (coord.): La Real Colegiata de Antequera. Cinco siglos de Arte e Historia. Antequera: Ayuntamiento, pp. 170-171.

- (2011): La escultura del Barroco. Málaga: Prensa Malagueña. (2020a): "Nuevas aportaciones sobre el escultor José Montes de Oca (16831754)". En: Cuadernos de los Amigos de los Museos de Osuna, 22, pp. 87-96. (2020b): Presencia antequerana en el barroco artístico sevillano: vecino de Sevilla desde que vine de Antequera. Discurso de ingreso de académico correspondiente en la Real Academia de Nobles Artes de Antequera. Antequera: Real Academia de Nobles Artes (en prensa).

Salazar y Bermúdez, María Dolores (1949): "Pedro Roldán, escultor". En: $A r-$ chivo Español de Arte, 88, pp. 317-340.

(1955): Breves aportaciones a la escultura religiosa en Andalucía a través de una figura representativa. Madrid.

Sancho Corbacho, Heliodoro (1950): El escultor sevillano Pedro Roldán y sus discípulos. Sevilla.

Sánchez López, Juan Antonio (2015): "El universo artístico. La escultura procesional en Antequera. Visiones y revisiones". En: Escalante Jiménez, José (coord.): Antequera, su Semana Santa. Antequera: ExLibric, pp. 47-124.

Santos Márquez, Antonio Joaquín (2009): "José Portillo (c. 1650-1685), un platero del Barroco andaluz". En: Morales, Alfredo (coord.): Actas del Congreso Internacional Andalucía Barroca, 2007. T. I. Sevilla: Consejería de Cultura de la Junta de Andalucía, pp. 431-440.

Torrejón Díaz, Antonio (2007): "El entorno familiar y artístico de La Roldana: el taller de Pedro Roldán”. En: Romero Torres, José Luis/ Torrejón Díaz, Antonio (coord.): Roldana, catálogo de la exposición. Sevilla: Consejería de Cultura de la Junta de Andalucía, p. 72. 


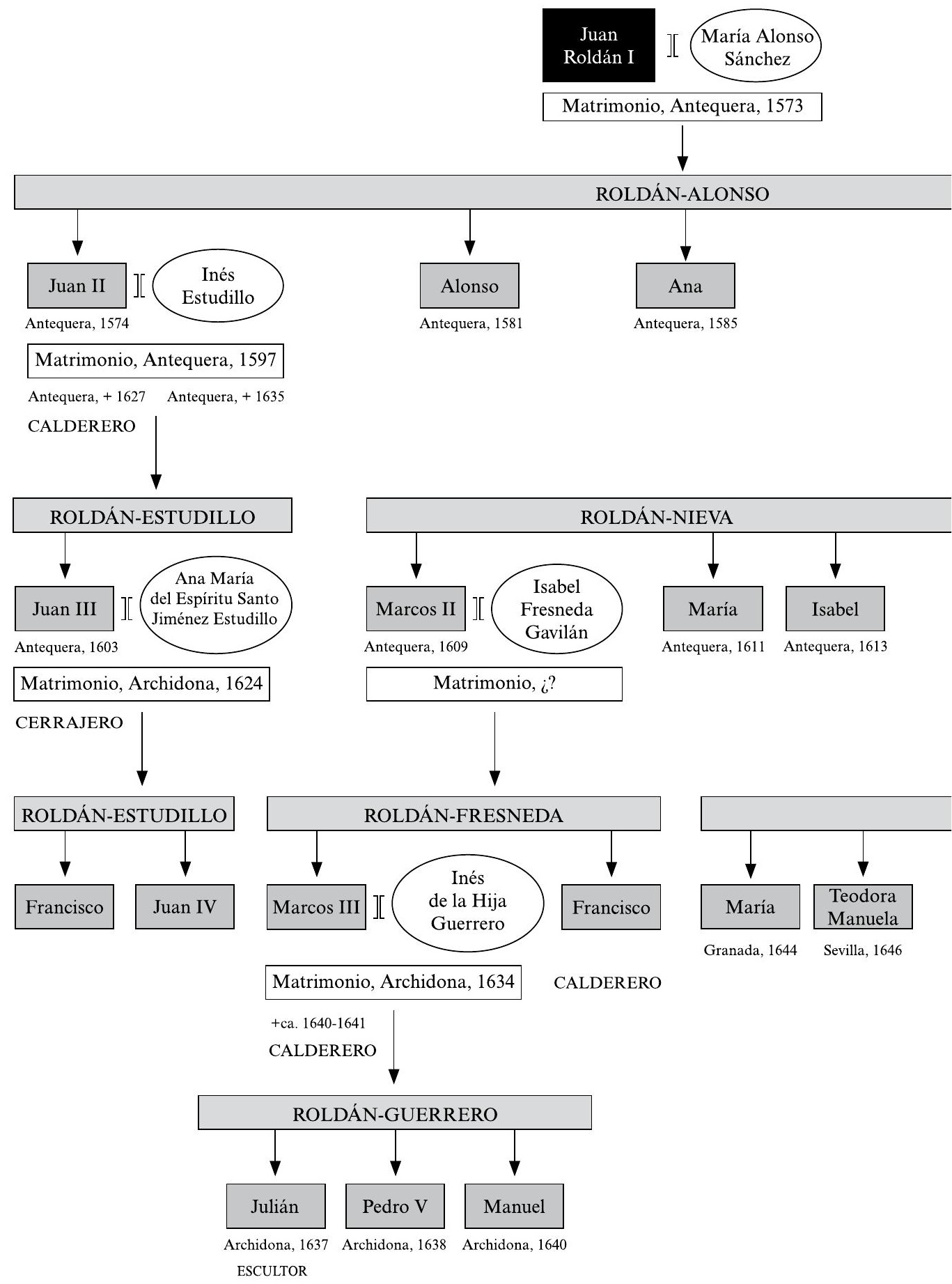




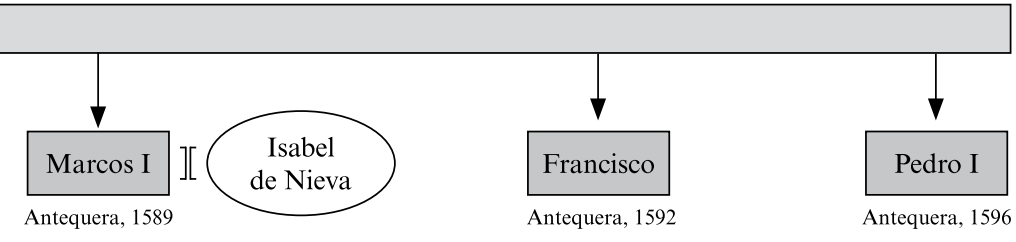

Matrimonio, Antequera, 1609

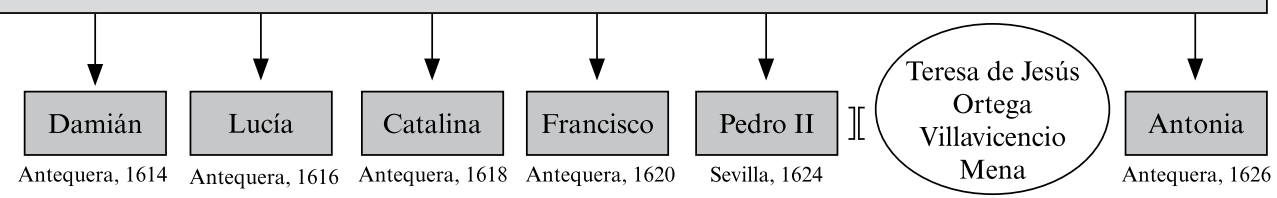

Matrimonio, Granada, 1642

ESCULTOR
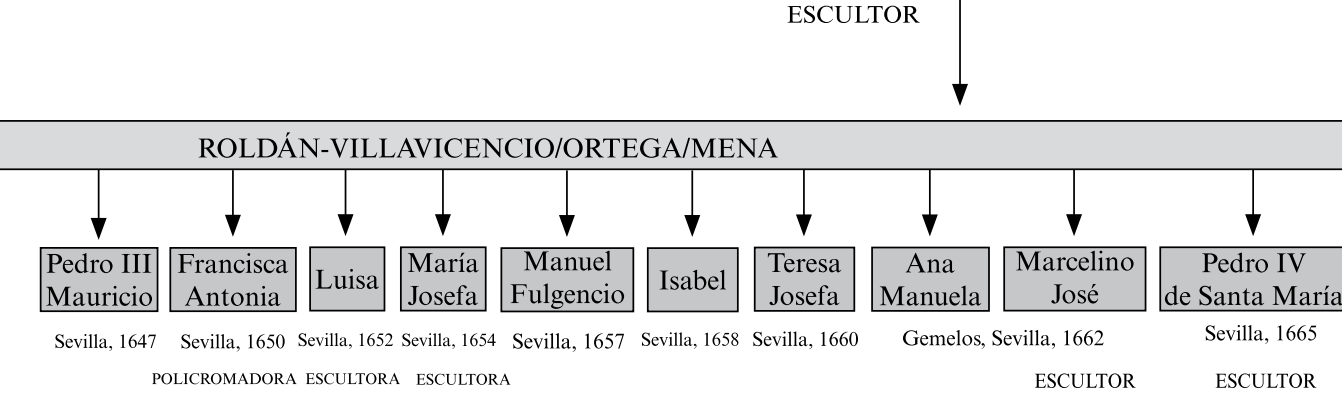

Figura 1. Árbol genealógico de la familia del escultor Pedro Roldán. 


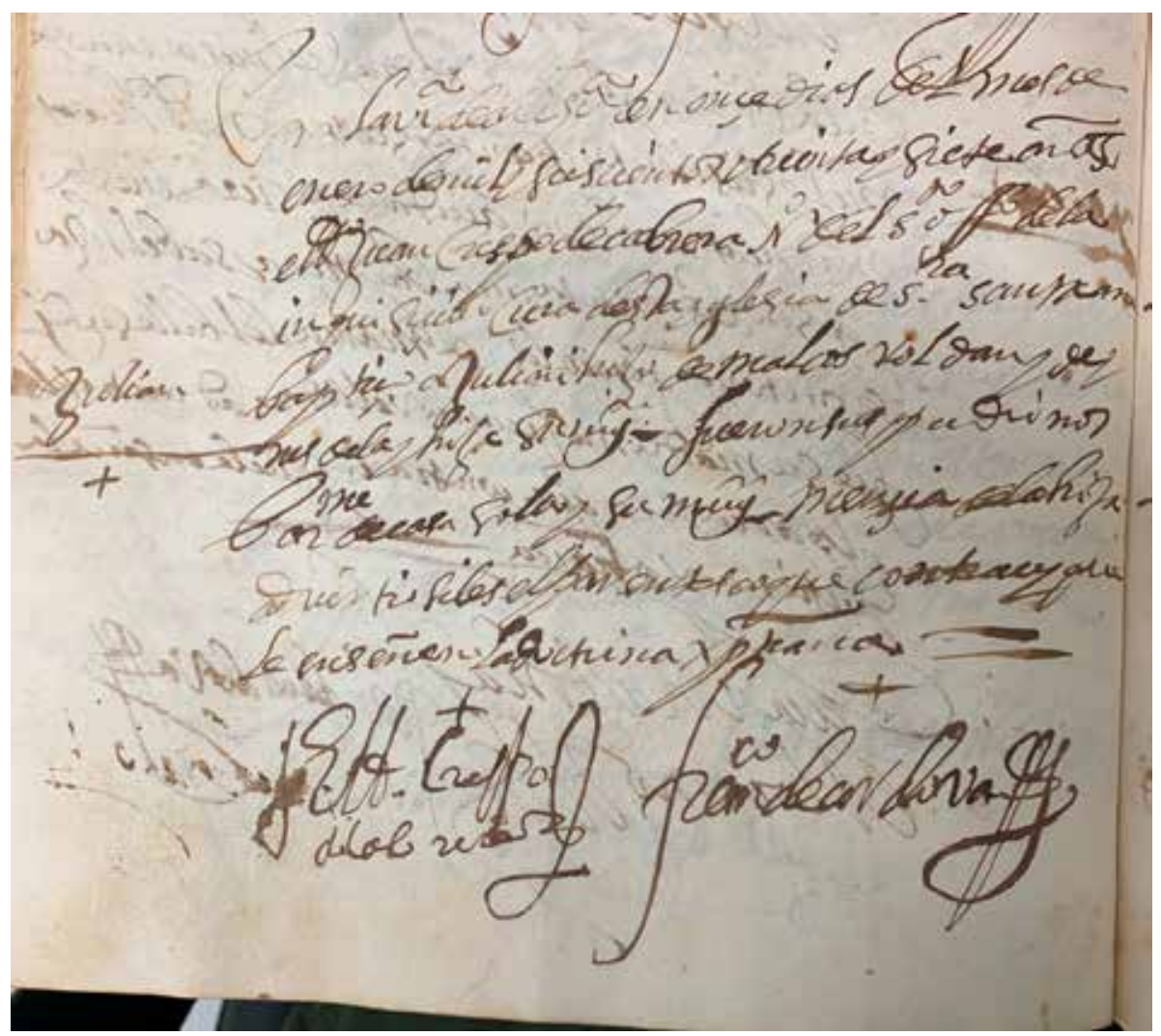

Figura 2. Partida de bautismo del escultor Julián Roldán Guerrero. 